Pesq. Vet. Bras. 35(8):709-715, agosto 2015 DOI: $10.1590 / \mathrm{S} 0100-736 \mathrm{X} 2015000800002$

\title{
Detecção dos genes codificantes da toxina CDT, e pesquisa de fatores que influenciam na produção de hemolisinas em amostras de Campylobacter jejuni de origem avícola ${ }^{1}$
}

\author{
Michele M. Trindade ${ }^{2 *}$, Gustavo Perdoncini ${ }^{3}$, Yuli M. Sierra-Arguello ${ }^{3}$, Maristela \\ Lovato $^{2}$, Anderlise Borsoi ${ }^{4}$ e Vladimir P. Nascimento ${ }^{3}$
}

\begin{abstract}
Trindade M.M., Perdoncini G., Sierra-Arguello Y.M., Lovato M., Borsoi A. \& Nascimento V.P. 2015. [Detection of the genes encoding the toxin CDT, and research factors which influence the production of hemolysin in Campylobacter jejuni from poultry products.] Deteç̧ão dos genes codificantes da toxina CDT, e pesquisa de fatores que influenciam na produção de hemolisinas em amostras de Campylobacter jejuni de origem avícola. Pesquisa Veterinária Brasileira 35(8):709-715. Laboratório Central de Diagnóstico de Patologia Aviária, Curso de Medicina Veterinária, Universidade Federal de Santa Maria, Campus Universitário, Santa Maria, RS 97105-900, Brazil. E-mail: michyvet@gmail.com

Thermophilic members of the Campylobacter genus are recognized as important enteropathogenics for humans and animals. The great variety of ecological habitats, such as water, food and milk, may promote new virulence factors. To detect the encoding genes distending cytolethal toxin (CDT) by PCR and study the hemolytic activity with influence of chelation solutions and ions, 45 Campylobacter jejuni samples from poultry production origin were used to perform the hemolytic research. To check the influence of chelation agents and solution of ions in the hemolytic activity, samples of $C$. jejuni strains were grown in tryptone soy broth TSB containing chelation agents separately EDTA, acetic acid, $\mathrm{CaCl}_{2}, \mathrm{MgCl}_{2}$ and $\mathrm{FeCl}_{3}$ ions solutions in microaerophilic atmosphere and then streaked on $5 \%$ sheep blood tryptic soy agar (TSA). To perform the detection of $c d t \mathrm{~A}, c d t \mathrm{~B}$ and $c d t \mathrm{C}$ genes the technique of Polymerase Chain Reaction (PCR) was used in 119 samples of $C$. jejuni from poultry production origin. We found $40 \%$ of samples showing hemolysis after growing with TSB. Only the acetic acid showed reduction in hemolysis. The prevalent gene profile was $c d t \mathrm{ABC}$ in $37.8 \%$ of the samples. It was observed that the results showed the presence of $C$. jejuni strains with virulent potential, due to presence of the CDT toxin genes and the hemolytic activity, which showed in vitro reduced when acetic acid was added.
\end{abstract}

INDEX TERMS: PCR, hemolytic activity, ions, chelants, CDT, Campylobacter jejuni.

RESUMO.- Membros termofílicos do gênero Campylobacter são reconhecidos como importantes enteropatógenos para o ser humano e animais. A grande diversidade ecológica

\footnotetext{
${ }^{1}$ Recebido em 11 de setembro de 2014.

Aceito para publicação em 6 de maio de 2015.

${ }^{2}$ Laboratório Central de Diagnóstico de Patologia Aviária, Curso de Medicina Veterinária, Universidade Federal de Santa Maria (UFSM), Campus Universitário, prédio 44, sala 5151, Santa Maria, RS 97105900, Brasil. *Autor para correspondência: michyvet@gmail.com

${ }^{3}$ Centro de Diagnóstico e Pesquisa em Patologia Aviária, Faculdade de Veterinária, Universidade Federal do Rio Grande do Sul (UFRGS), Av. Bento Gonçalves 9090, Porto Alegre, RS 91540-000, Brasil.

${ }^{4}$ Departamento de Patologia Experimental e Comparada, Faculdade de Medicina Veterinária e Zootecnia, Universidade de São Paulo (USP), Av. Prof. Dr. Orlando Marques Paiva 87, Cidade Universitária, São Paulo, SP 05 508-270, Brasil.
}

destes micro-organismos em diferentes habitats tais como água, animais e alimentos predispõem ao aparecimento de novos fatores de virulência. Este trabalho teve por objetivo detectar os genes codificantes da Toxina Distensiva Citoletal (CDT) por meio da técnica de PCR, pesquisar a atividade de hemolisinas e a influência de soluções quelantes e de íons nesta atividade. Foram utilizadas 45 amostras de Campylobacter jejuni de origem avícola para pesquisa de atividade hemolítica, cultivadas em Caldo Triptona de Soja (TSB). Após o crescimento bacteriano, as amostras foram semeadas em Ágar tríptico de soja (TSA) contendo 5\% de sangue de ovino. Para verificar a influência de agentes quelantes e solução de íons na atividade hemolítica, as amostras de $C$. jejuni foram cultivadas em TSB contendo separadamente os quelantes EDTA, ácido acético, soluções de 
íons $\mathrm{CaCl}_{2}, \mathrm{MgCl}_{2}$ e $\mathrm{FeCl}_{3}$, em atmosfera de microaerofilia. Quanto à atividade de hemolisina de $C$. jejuni em placas de TSA - sangue ovino foi possível observar que houve hemólise em $40 \%$ das amostras analisadas apenas com caldo TSB. Somente o ácido acético apresentou ação quelante sobre a atividade de hemolisinas em amostras de $C$. jejuni semeadas em placas de TSA - sangue ovino. Para detecção dos genes $c d t \mathrm{~A}, c d t \mathrm{~B}$ e $c d t \mathrm{C}$ através da técnica da Reação em Cadeia da Polimerase (PCR) foram utilizadas 119 amostras de C. jejuni de origem avícola. Foi possível observar que 37,8\% possuíam o perfil de genes $c d t A B C$. Os resultados demonstraram em amostras avícolas a presença de cepas de $C$. jejuni com potencial virulento, devido à presença dos genes da toxina CDT e potencial hemolítico, que apresentou ação reduzida in vitro com ácido acético.

TERMOS DE INDEXAÇÃO: PCR, atividade hemolítica, íons, quelantes, CDT, Campylobacter jejuni.

\section{INTRODUÇÃO}

Quando se considera o alimento de origem avícola, deve-se avaliar o estado sanitário dos plantéis, o que reflete na qualidade do alimento produzido. Frangos de corte estão entre os principais carreadores de patógenos em abatedouros e apresentam alta correlação com a contaminação cruzada por Salmonella spp. e Campylobacter sp. (Fao/Who 2009). A legislação atual do Brasil regula o controle de Salmonella spp. em carcaças de frangos (Brasil 2003), porém para Campylobacter sp. não há legislação vigente para sua avaliação e que regulamente seu controle tanto em lotes de frangos de corte como em seus produtos.

A família Campylobacteraceae é composta de três gêneros: Campylobacter, Arcobacter e Sulfuropirullum. 0 gênero Campylobacter possui uma taxonomia complexa e que ainda se encontra em evolução (Feistel et al. 2013). As espécies Campylobacter jejuni, C. coli, C. lari, C. upsaliensis e $C$. helveticus formam um grupo geneticamente próximo e são frequentemente isolados de animais e do homem com diarreia (Silva et al. 2011). Dentre as espécies enteropatogênicas, $C$. jejuni recebe maior atenção, estimando-se que cerca de $90 \%$ dos casos de campilobacteriose em humanos sejam causados por esse agente bacteriano (Wassenaar \& Newll 2000). São tipicamente bactérias microaerófilas, requerem cultivo em 5 a $7 \%$ de $\mathrm{O}_{2}$ e em 3 a $5 \%$ de $\mathrm{CO}_{2}$. 0 cultivo é difícil, sendo altamente sensível às condições ambientais como temperatura, ressecamento e tensão de oxigênio. A faixa de pH ótimo está em 6,5 a 7,5. Em função da produção ou não da catalase, as espécies do gênero dividem-se em dois grupos, sendo o grupo das produtoras de catalase onde se encontram as espécies importantes do ponto de vista patogênico. Quanto à capacidade de crescimento acima da temperatura de $37^{\circ} \mathrm{C}$, algumas espécies apresentam um crescimento preferencial a $42^{\circ} \mathrm{C}$, pertencendo ao grupo chamado termofílico ou termotolerante ao qual fazem parte espécies envolvidas nos processos gastroentéricos (Carvalho 2007, Back 2010).

As bactérias termofílicas pertencentes a este gênero, entre eles $C$. jejuni, representam um dos mais importantes enteropatógenos para a Saúde Pública, principalmente, nos países desenvolvidos. Nos Estados Unidos da América (EUA) foram estimados mais de 845 mil casos de campilobacteriose em 2011, colocando este micro-organismo na lista dos cinco patógenos que mais causam doenças de origem alimentar no país, estando atrás somente de Norovírus e Salmonella spp. (Scallan et al. 2011), com o custo estimado de 1,7 bilhões de dólares com tratamento dos pacientes infectados por Campylobacter (Bessède et al. 2014). No Reino Unido foram estimados mais de 320.000 casos de gastroenterites causadas por Campylobacter spp., somente na Inglaterra e País de Gales no ano de 2008 (FSA 2011) e para a totalidade dos países da União Europeia, dados da European Food Safety Authority (FSA 2011) descrevem que ocorrem anualmente nove milhões de casos de campilobacteriose humana, que resultam em custos totais anuais de 2,4 bilhões de Euros.

O reservatório natural de Campylobacter são as aves que podem eliminar em cada grama de fezes, quantidades superiores a $10^{6}$ bactérias, revelando sua importância na disseminação para o ambiente (Altekruse et al. 1994). A preocupação está no potencial das aves em transmitir ao homem através dos alimentos de origem animal. 0 consumo de frangos e derivados de aves representa a forma mais comum de aquisição da gastroenterite mundialmente, estimando-se sua implicação em 50 a 70\% das infecções esporádicas (Canals \& Rosell 2002). Trabalhos realizados no Brasil demonstram frequência elevada dessa bactéria em produtos avícolas. No Rio Grande do Sul Boufleur (2009) encontrou positividade em $61,1 \%$ em amostras frescas de fígado, coração, moela e asa coletados em supermercados. No Rio de Janeiro, Medeiros (2011) detectou a presença de Campylobacter sp. em 70\% das amostras oriundas de carcaças refrigeradas. Perdoncini (2012) analisou carcaças após o chiller e, $72 \%$ das amostras estavam contaminadas por Campylobacter sp., deste total $82 \%$ era composto por $C$. jejuni e $8 \%$ por C. coli.

Quando da infecção por Campylobacter no homem, a reação inflamatória e a bacteremia são muitas vezes observadas e sugerem fortemente que a invasão celular é um importante passo no mecanismo patogênico, embora a habilidade e a intensidade de invasão de Campylobacter pareça ser cepa-dependente (Van Vliet \& Ketley 2001). Um dos principais fatores de virulência relacionados à patogênese do Campylobacter spp. (C. coli, C. fetus, C. jejuni e C. lari) em infecções animais e humana é denominado Toxina Citoletal Distensiva (CDT) (Martinez et al. 2006). A CDT é determinada por um cluster de três genes adjacentes $c d t \mathrm{~A}, c d t \mathrm{~B}$ e $c d t C$ os quais codificam, respectivamente, proteínas de 30 , 29 e 21 kDa (Lara-Tejero \& Galán 2001). A proteína produzida pelo gene $c d t B$ potencializa o bloqueio do ciclo celular; e as proteínas dos genes $c d t \mathrm{~A}$ e $c d t C$ transportam a proteína do $c d t \mathrm{~B}$ e a interiorizam na célula hospedeira. Uma vez dentro da célula a proteína $c d t \mathrm{~B}$ entra no núcleo e exibe uma atividade de corte no DNA dupla fita. As células eucarióticas respondem aos cortes no DNA, bloqueando a fase G2/M da divisão celular, induzindo uma distensão citoplasmática que leva à morte da célula (Dasti et al. 2010). A presença dos três genes de $c d t$ é requerida para plena atividade da toxina (Asakura et al. 2007). No entanto, mutações podem 
ocorrer nos genes $c d t \mathrm{~A}, c d t \mathrm{~B}$ e $c d t \mathrm{C}$ causando perda da função em alguma das três subunidades, impedindo a célula bacteriana de induzir citoxicidade (Smith \& Bayles 2006).

Outro fator de virulência discutido em $C$. jejuni é a produção de hemolisinas. Van Vliet \& Ketley (2001) relatam a existência de genes contendo domínios para citotoxina hemolítica que, diferentemente de muitas outras toxinas, não é internalizada pelas células, atuando como agente ativo de membranas levando à lise e morte celular, principalmente de eritrócitos. Hemolisinas não são líticas apenas aos eritrócitos, causam danos também aos fibroblastos, plaquetas, monócitos, granulócitos e células endoteliais e do miocárdio (Rowe \& Welch 1994). Já tendo sido documentada a Síndrome urêmica hemolítica como uma complicação de gastroenterite por $C$. jejuni em humanos (Chamovitz et al. 1983). Embora Campylobacter não seja considerado hemolítico em ágar sangue, algumas cepas apresentaram atividade hemolítica (Misawa et al. 1995). Em 1993, Hossain et al. analisaram a atividade hemolítica em diferentes eritrócitos na tentativa de avaliar a cinética de ativação da hemolisina produzida por C. jejuni. Em 1995, Misawa e colaboradores pesquisaram as condições ideais (temperatura da cultura, pH médio, concentração de $\mathrm{CO}_{2}$, período de incubação, meio utilizado) e a frequência da produção de hemolisinas em amostras de $C$. jejuni de origem humana e não humana, obtendo em $100 \%$ das mesmas, atividade hemolítica.

Em decorrência da importância de $C$. jejuni na saúde pública o presente trabalho teve por objetivo pesquisar a atividade hemolítica e influência de soluções quelantes e de íons nesta atividade e, detectar a presença dos genes $c d t \mathrm{~A}$, $c d t \mathrm{~B}$ e $c d t \mathrm{C}$ codificantes da toxina CDT em amostras de $C$. jejuni de origem avícola.

\section{MATERIAL E MÉTODOS}

\section{Procedência das amostras de campo}

As amostras de Campylobacter jejuni estudadas foram oriundas da bacterioteca do Centro de Diagnóstico e Pesquisas em Patologia Avícola da Universidade Federal do Rio Grande do Sul (CDPA/UFRGS), provenientes de isolados de matadouros-frigoríficos de aves, sob Inspeção Federal.

\section{Manutenção das amostras}

As amostras de $C$. jejuni estavam estocadas em tubos contendo Caldo Brucella, acrescidas de $25 \%$ de glicerol e mantidas em biofreezer a temperatura de $-80^{\circ} \mathrm{C}$. As amostras foram recuperadas através do enriquecimento em Caldo Bolton, cultivadas em ágar Carvão Cefoperazone Desoxicolato modificado mCCDA e incubadas por $48 \mathrm{~h}$ em temperatura de $41,5^{\circ} \mathrm{C}$, sob ambiente de microaerofilia (Microaerobac - Probac ${ }^{\circledR}$ ).

\section{Detecção da atividade hemolítica}

Pesquisa de hemolisina em meio sólido. Foram utilizadas 45 amostras de $C$. jejuni, as quais foram cultivadas em caldo Triptona de soja (TSB) e incubadas a $41,5^{\circ} \mathrm{C}$ por 48 h. Após o crescimento bacteriano, as amostras foram semeadas em Ágar tríptico de soja (TSA) contendo $5 \%$ de sangue de ovino. 0 resultado foi considerado positivo quando observada a presença de halo hemólise ao redor ou sob as colônias. A leitura foi realizada no segundo dia de incubação em atmosfera de microaerofilia comercial (Microarebac - Probac $^{\circledR}$ ), segundo metodologia descrita por Misawa (1995).
Influência da condição de cultivo na detecção de atividade hemolítica com quelantes e soluções de íons. Para verificar a influência de agentes quelantes e solução de íons na expressão da atividade hemolítica, as amostras de $C$. jejuni foram cultivadas em TSB contendo separadamente os quelantes EDTA (etilenoadiamina-tetra ácido acético, Synth - 5mM) e $\mathrm{FeCl} 3$ (Cloreto férrico - 5mM) (Baratéia et al. 2001); ácido acético (Sigma - 100g); solução de íons $\mathrm{CaCl}_{2}$ (Cloreto de cálcio - $10 \mathrm{mM}$ )e $\mathrm{MgCl}_{2}$ (Cloreto de Magnésio - 10mM) (Boehm et al. 1990) a $41,5^{\circ} \mathrm{C}$ por $48 \mathrm{~h} \mathrm{em}$ atmosfera de microaerofilia comercial. Após a incubação as amostras foram semeadas, como descrito anteriormente. Como controle dos testes foi utilizado somente o caldo TSB sem inoculação bacteriana, acrescido dos agentes químicos em teste.

Detecção dos genes cdtA, cdtB e cdtC através da técnica da Reação em Cadeia da Polimerase (PCR)

A obtenção do DNA bacteriano de 119 amostras de C. jejuni foi realizada através de lise térmica seguindo protocolo de Blanco et al. (1997). Foram utilizadas como controle positivo a cepa $C$. jejuni ATCC 33560 e como controle negativo uma cepa de Arcobacter sp. Os primers ou oligonucleotídeos utilizados foram baseados em trabalhos anteriores (Datta et al. 2003, Wieczorek \& Osek 2008), sendo cdtA F 5' CCTTGTGATGCAAGCAATC 3' - cdtA $R$ 5' ACACTCCATTTGCTTTCTG 3'; $c d t$ B F 5' CAGAAAGCAAATGGAGTGTT 3' - $c d t$ B R 5' AGCTAAAAGCGGTGGAGTAT 3' e $c d t C$ F 5' CGATGAGTTAAAACAAAAAGATA 3' e $c d t C$ R 5' TTGGCATTATAGAAAATACAGTT 3'.

A pesquisa dos genes $c d t A$ e $c d t C$ foram realizadas de acordo com descrito por Datta et al. (2003) adaptando a concentração $\mathrm{MgCl}_{2}$ para $1 \mathrm{mM}$ e a pesquisa do gene $c d t \mathrm{~B}$ foi realizada como descrita por Wieczorek \& Osek (2008) com concentração de $\mathrm{MgCl}_{2}$ adaptada de 1,5mM. Após amplificação em Termociclador (Biocycler - Peltier Thermal Cycler MJ96+MJ96G), os produtos de PCR foram submetidos à eletroforese realizada em gel de agarose a $2 \%$ corado com brometo de etídio. Os fragmentos do DNA amplificados foram visualizados em trans-iluminador ultravioleta, para identificar bandas de $370 \mathrm{pb}$ para o gene $c d t \mathrm{~A}, 620 \mathrm{pb}$ para o gene $c d t \mathrm{~B}$ e $182 \mathrm{pb}$ para o gene $c d t \mathrm{C}$.

\section{Análise estatística}

Os dados de presença de halos de hemólise versus as soluções quelantes e ou de íons foram analisados utilizando-se o teste de comparação de médias Tukey, com nível de significância de 95\% utilizando software BioStat, 2009 (Analyst Soft Inc. ${ }^{\circledR}$ ).

\section{RESULTADOS}

0 resultado do teste de averiguação da atividade hemolítica das 45 amostras de Campylobacter jejuni pode ser observado no Quadro 1. As amostras do grupo TSB sem adição de agentes quelantes ou íons apresentaram maior atividade hemolítica quando estriadas em ágar e, menor atividade hemolítica foi apresentada para as amostras em que TSB foi suplementado com ácido acético. Quando utilizado $\mathrm{CaCl}_{2}$, $\mathrm{FeCl}_{3}$ ou EDTA houve menor atividade hemolítica do que quando utilizado apenas o caldo TSB, mas ainda maior que quando utilizado o ácido acético. 0 caldo TSB com $\mathrm{MgCl}_{2}$ apresentou diferença somente em relação ao caldo TSB, demonstrando menor percentual hemolítico.

Os resultados observados nas 119 amostras analisadas por meio do método de PCR demonstraram que em 17 amostras não foram detectados os genes pesquisados. Para as 102 amostras positivas para um ou mais genes pesquisados, o perfil prevalente foi da presença dos três 
Quadro 1. Análise da média percentual da influência de agentes quelantes e íons em caldo TSB na atividade hemolítica de amostras de Campylobacter jejuni material de origem avícola, quando semeadas em TSA+ sangue ovino

\begin{tabular}{cc}
\hline $\begin{array}{c}\text { Caldo TSB adicionado de agente } \\
\text { quelantes ou íons }\end{array}$ & $\begin{array}{c}\text { Amostras com atividade } \\
\text { hemolítica (\%) }\end{array}$ \\
\hline TSB & $40 \mathrm{a}$ \\
TSB+CaCl2 & $22,23 \mathrm{c}$ \\
TSB+FeCl3 & $20,74 \mathrm{c}$ \\
TSB+EDTA & $25,79 \mathrm{c}$ \\
TSB+Ácido Acético & $7,41 \mathrm{~b}$ \\
TSB+MgCl2 & $20 \mathrm{bc}$
\end{tabular}

$\mathrm{TSB}=$ Caldo triptona de soja; $\mathrm{CaCl} 2=$ Cloreto de cálcio; $\mathrm{FeCl} 3=$ Cloreto férrico; $\mathrm{EDTA}$ = etilenoadiamina-tetra ácido acético; $\mathrm{MgCl} 2$ = Cloreto de Magnésio.

$\mathrm{a}, \mathrm{b}, \mathrm{c}$ Letras diferentes significam que resultados apresentam uma diferença estatística com $\mathrm{p}<0,05$.

Quadro 2. Perfil de genes cdtABC em 119 amostras de Campylobacter jejuni isoladas de material de origem avícola

\begin{tabular}{lll}
\hline Perfil de genes cdt & Numero de amostras & Percentual de amostras (\%)
\end{tabular}

$\begin{array}{ccc}\text { ABC } & 45 & 37,8 \\ \text { AB } & 1 & 0,8 \\ \text { AC } & 23 & 19,3 \\ \text { BC } & 1 & 0,8 \\ \text { A } & 1 & 0,8 \\ \text { B } & 17 & 14,3 \\ \text { C } & 14 & 11,8 \\ c d t \text { negativo } & 17 & 14,3 \\ \text { Total } & 119 & 100\end{array}$

genes, ou seja, cdtABC. Os dados podem ser observados no Quadro 2, Figura 1 e 2.

Analisando-se as combinações de perfis de genes $c d t A-$ $\mathrm{BC}$ e a atividade hemolítica nos diferentes meios de crescimento testados foi observada a hemólise estatisticamente diferente para as amostras $C$. jejuni com o perfil de genes
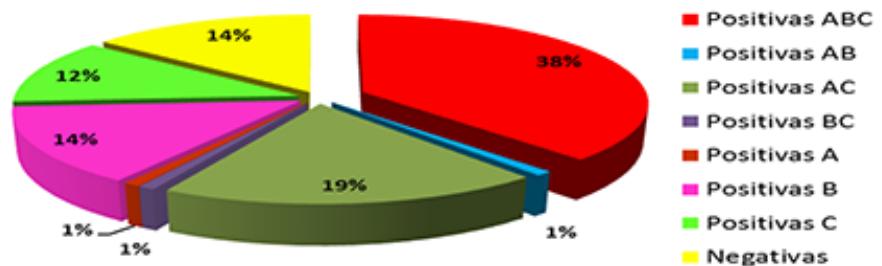

Fig.1. Resultados obtidos pela amplificação por PCR para detecção dos genes $c d t \mathrm{~A}, c d t \mathrm{~B}$ e $c d t \mathrm{C}$ nas amostras de Campylobacter jejuni de origem avícola.

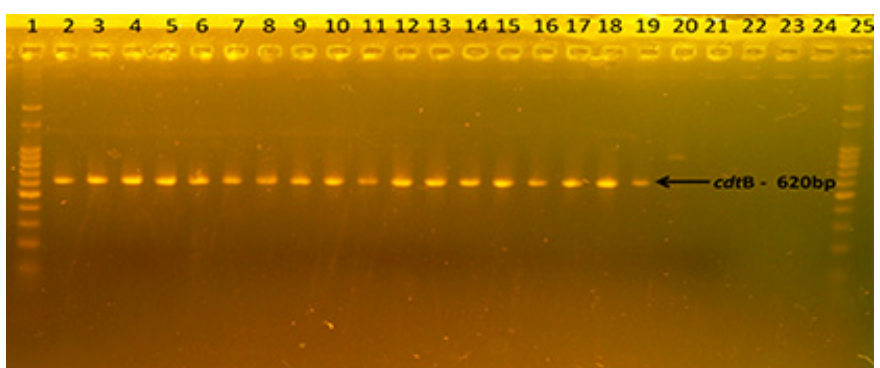

Fig.2. Resultados obtidos por PCR para identificação dos genes codificantes da toxina CDT em gel de agarose 2\% em UV. 1 e 25 = marcador, $2=$ controle positivo, 3 a $19=$ amostras posi tivas para $c d t \mathrm{~B}, 20$ a $23=$ amostras negativas para $c d t \mathrm{~B}, 24=$ controle negativo.
cdtABC cultivadas em TSB não suplementado e em TSB suplementado com $\mathrm{FeCl}_{3}$. No caldo suplementado com $\mathrm{CaCl}_{2}$ as amostras com os genes cdtABC e cdtAC concomitantes apresentaram estatisticamente maior percentagem de atividade hemolítica. Para os suplementos EDTA, $\mathrm{MgCl}_{2}$ e ácido acético não houve diferenças quanto à presença de diferentes genes e atividade hemolítica, como demonstrado no Quadro 1.

\section{DISCUSSÃO}

A produção de trabalhos científicos abordando esse importante enteropatógeno no Brasil é inferior aos destinados a outros patógenos, tornando assim necessários estudos em diversos campos da biologia desta bactéria para melhor entendimento do comportamento, epidemiologia e fatores críticos no desenvolvimento desta zoonose. Dentre as dificuldades que envolvem a pesquisa de Campylobacter, cita-se como fator preponderante, as próprias características biológicas deste micro-orgamismo, que o torna particularmente distinto da maioria dos enteropatógenos bacterianos, requerendo condições únicas para seu isolamento e identificação. Outro aspecto importante que deve ser ressaltado é que o Campylobacter é uma zoonose, naturalmente transmitida de animais vertebrados para o homem, tendo como principais veículos de transmissão o alimento de origem animal, a água com contaminação fecal recente, ou ainda mais raramente, o contato direto com animais portadores ou doentes (Frost 2001).

Para as bactérias do gênero Campylobacter, dentre outros fatores, a produção de hemolisinas e de enterotoxinas são consideradas importantes para a virulência das cepas (Simi 2004), sendo que Van Vliet \& Kitley em 2001 relataram a existência de genes contendo domínios específicos para hemolisinas. Tay et al. (1995) ao pesquisar atividade hemolítica em 100 amostras de Campylobacter spp., C. jejuni e $C$. coli de origem humana e animal observaram presença em $56 \%$ dos isolados e sugeriram que esta atividade possa ser um importante fator de virulência contribuindo para a gastroenterite por Campylobacter e suas complicações. No presente estudo, 40\% das amostras de Campylobacter de origem avícola analisadas também apresentaram atividade hemolítica (Quadro 1).

Ainda, Hossain et al. (1993) detectaram atividade hemolítica em amostras oriundas de quadros clínicos de diarreia em humanos, mostrando que as amostras se comportavam com diferentes aspectos possuindo atividade máxima com eritrócitos de coelho e atividade mínima com eritrócitos de galinha. Misawa et al. (1995) pesquisaram determinados fatores que contribuíam positivamente para atividade hemolítica como variação de pH e de concentração de $\mathrm{CO}_{2}$ utilizada na atmosfera de incubação. A influência de agentes quelantes nos meios de cultura e atividade hemolítica também foi analisada por diversos pesquisadores (Carbonell \& Vidotto 1992, Chart et al. 1998). Thomé (2006) observou aumento de atividade hemolítica em amostras de $C$. jejuni, quando utilizado $\mathrm{FeCl}_{3}$ e TSA-sangue ovino. No presente trabalho obteve-se resultados diferentes, o uso $\mathrm{FeCl}_{3}$ inibiu a atividade. No entanto, os resultados estão de acordo com o que afirma Baratéia et al. (2001) em estudos da atividade 
hemolítica em Plesiomonas shigelloides, nas quais a síntese de hemólise também está parcialmente regulada por íons de ferro, e a produção máxima ocorre em condições de limitação de ferro.

Pickett (1992) testou a habilidade de amostras de $C$. jejuni em adquirir ferro a partir de várias fontes presentes no metabolismo humano quando crescidas em meios sem fontes de ferro e concluiu que a atividade hemolítica não demonstrava ser regulada por íons ferro, uma vez que as amostras demonstraram ser incapazes de retirar ferro dessas substâncias. Com o uso de EDTA Boehm et al. (1990) obtiveram resultados diferentes deste estudo quando pesquisaram atividade hemolítica em Escherichia coli, em que o $\mathrm{CaCl}_{2}$ é necessário para atividade in vitro de hemolisina, não sendo inibida quando utilizado EDTA no mesmo meio. Também, Baratéia et al. (2001) descrevem o cálcio como sendo essencial para ativação de $\alpha$-hemolisina, para a sua estabilidade e para a ligação da toxina às membranas dos eritrócitos.

Em um trabalho realizado por Simi (2004) não foi observada alteração na atividade hemolítica com o uso de EDTA em pesquisa com outra enterobactéria, Enterobacter cloacae, diferente do ocorrido no presente trabalho. Em relação ao $\mathrm{CaCl}_{2}$, há trabalhos que afirmam que para que haja atividade hemolítica não é necessária a adição de íons de cálcio, sugerindo que os meios de cultura utilizados contenham cálcio suficiente para hemólise (Chart et al. 1998). Baratéia et al. (2001) observaram que o uso de $\mathrm{CaCl}_{2} \mathrm{e}$ EDTA aumentava significativamente a atividade hemolítica, sugerindo que $P$. shigelloides requeira íons cálcio da mesma maneira que E. coli para atividade hemolítica.

0 uso do ácido acético como sanitizante já foi demonstrado por Berrang et al. (2006), que com o intuito de reduzir a contaminação em carcaças em frangos de corte por Campylobacter, adicionaram ácido acético, acido lático e ácido propiônico na cloaca dos animais antes da escalda e verificaram a redução da contaminação pelo agente. 0 mesmo foi possível observar quando utilizado no presente estudo, bem como a diminuição de atividade hemolítica, comprovando seu potencial sanitizante.

Quanto a toxinas em Campylobacter spp., a toxina CDT contribui para a patogênese através da inibição da imunidade humoral e celular via apoptose das células de resposta imune, podendo gerar necrose do epitélio celular e fibroblastos envolvidos na reparação de lesões produzidas por patógenos, resultando em lenta cicatrização e indução de sintomas da doença (Smith \& Bayles 2006). Portanto, interfere na divisão e diferenciação das células das criptas intestinais, contribuindo para o desenvolvimento da diarreia (Park 2002).

A atividade da toxina CDT é codificada pelos genes $c d t$, que, no caso de $C$. jejuni, consistem em três genes adjacentes denominados $c d t \mathrm{~A}, c d t \mathrm{~B}$ e $c d t C$ (Martinez et al. 2006), sendo que a presença dos três genes é requerida para a plena atividade da toxina (Asakura et al. 2007). Os resultados obtidos em relação aos genes $c d t$ neste trabalho são diferentes dos encontrados na literatura consultada, que relata frequências geralmente próximas a $100 \%$ para os três genes: $c d t \mathrm{~A}, c d t \mathrm{~B}$ e $c d t \mathrm{C}$.
Datta et al. (2003) obtiveram 100\% de frequência para os três genes a partir de amostras de origem humana, avícola e bovina e Rozynek et al. (2005) também obtiveram uma frequência de $100 \%$ em amostras pesquisadas a partir de suabes de crianças com diarreia e de carcaças de frangos obtidos de supermercados e matadouros em diversas regiões da Polônia. Wieczorek \& Osek (2008) relataram, em amostras de fezes de aves, $76,6 \%$ positivos para $c d t \mathrm{~A}$, $85,3 \%$ para $c d t \mathrm{~B}$ e $83,2 \%$ para $c d t \mathrm{C}$. Martinez et al. (2006) em suas pesquisas encontraram os três genes em $98 \%$ das cepas isoladas. Talukder et al. (2008) identificaram os três genes $c d t$ em $98 \%$ das amostras de C. jejuni de origem humana (diarreia) e Van Deun et al. (2007) encontraram os genes em $100 \%$ das amostras de origem humana e avícolas, concordando com Wardak \& Szych (2006) que afirmaram que a toxina CDT está associada com as cepas causadoras de enterites em humanos, indicando que os genes são importantes fatores de virulência.

Por outro lado, Carvalho et al. (2010) ao pesquisarem C. jejuni em carcaças de aves, relataram todos os genes do complexo CDT em apenas 36,4\% das amostras. Resultado esse mais próximo do encontrado no presente estudo. Também Hanel et al. (2007) pesquisaram na Alemanha a toxina CDT em amostras provenientes de perus e encontraram os três genes em $53 \%$ das cepas pesquisadas de $C$. jejuni. No Japão, Kabir et al. (2011) analisaram amostras a partir de fezes de pacientes com diarreia, das quais quatro foram positivas para $C$. jejuni e os três genes CDT.

Segundo Martinez et al. (2006) todas as cepas de C. jejuni apresentam genes $c d t$, e a maioria têm atividade da toxina, porém, há exceções de isolamentos que sofrem mutações e não expressam a atividade do gene. Asakura et al. (2007) também observaram que alguns genes $c d t$ não são identificados devido a mutações como deleção, inserção ou substituição de nucleotídeos e sugerem que essas mutações possam afetar a atividade da toxina. Bang et al. (2003) relataram que a produção da toxina é baixa ou negativa quando há mutações em regiões de codificação dos genes $c d t$, podendo influenciar a hibridização de iniciadores na PCR de CDT, bem como na produção. Segundo Park (2002), mesmo algumas cepas sendo CDT negativas mutantes, ainda mantêm alguma atividade toxigênica. Podendo, com base nesses dados, ser dada sequência ao presente trabalho, com avaliação mais aprofundada dos resultados, a fim de comprovar possíveis mutações para os genes $c d t$ nas amostras pesquisadas e/ou novas análises utilizando-se métodos como RT-PCR (transcrição reversa) e/ou Western blotting. Abu Oun et al. (2005) realizaram uma pesquisa utilizando estes métodos a fim de identificar mutações, deleções e/ou inserções em amostras humanas e avícolas CDT-negativa comprovando que essas alterações tornaram os genes CDT não detectáveis por outro método, mas não sendo excluída sua presença.

\section{CONCLUSÕES}

0 presente trabalho demonstrou a presença dos três genes CDT ( $c d t \mathrm{~A}, c d t \mathrm{~B}$ e $c d t \mathrm{C}$ ) na maioria das amostras pesquisadas e ainda, na maioria das amostras com atividade hemolítica. 
Também demonstrou que o ácido acético reduziu a atividade hemolítica das amostras, sugerindo potencial uso no controle da virulência da bactéria.

Os presentes dados contribuem para conhecimento e caracterização fenotípica e genotípica de Campylobacter jejuni e como embasamento para futuro desenvolvimento de formas de minimizar a incidência de $C$. jejuni e melhorar a qualidade microbiológica em produtos de origem avícolas, uma vez que esse micro-organismo possa vir a tornar-se uma barreira sanitária na produção de aves.

\section{REFERÊNCIAS}

Abu Oun M., Manning G., Cawthraw S.A., Ridley A., Ahmed I.H., Wassennar T.M. \& Newell D.G. 2005. Cytolethal Distending Toxin (CDT): negative Campylobacter jejuni strains and anti-CDT neutralizing antibodies are induced during human infection but not during colonization in chickens. Infect. Immun. 73(5):3053-3065.

Altekruse S.F., Hunt J.M., Tollefson L.K. \& Madden J.M. 1994. Food and animal sources of human Campylobacter jejuni infection. J. Am. Vet. Med. Assoc. 204(1):57-61.

Asakura M., Samosornsuk W., Taguchi M., Kobayashic K., Misawa N., Kusumoto M., Nishimura K., Matsuhisa A. \& Yamasaki S. 2007. Comparative analysis of cytolethal distending toxin $(c d t)$ genes among Campylobacter jejuni, C. coli and C. fetus strains. Microbiol. Pathog. 42:174-183.

Back A. 2010. Campilobacteriose, p.119-122. In: Back A. (Ed.), Manual de Doenças de Aves. 2ª ed. Integração, Cascavel.

Bang D.D., Nielsen E.M., Scheutz F., Pedersen K., Handberg K. \& Madsen M. 2003. PCR detection of seven virulence and toxin genes of Campylobacter jejuni and Campylobacter coli isolates from Danish pigs and cattle and cytolethal distending toxin production of the isolates. J. Appl. Microbiol. 94:1003-1014.

Baratéia R.C., Saridakis H.O., Gaziri L.C.J. \& Pelayo J.S. 2001. Effects of medium composition, calcium, iron and oxygen on haemolysin production by Plesiomonas shigelloides isolated from water. J. Appl. Microbiol. 90: 482-487.

Berrang M.E., Smith D.P. \& Hilton Jr A. 2006. Organic acids placed into the cloaca to reduce Campylobacter contaminationof broiler skyn during defeathering. J. Appl. Poult. Res. 15:287-291.

Bessède E., Lehours P., Labadi L., Bakari S. \& Mégraud F. 2014. Comparison of characteristics of patients infected by Campylobacter jejuni, Campylobacter coli and Campylobacter fetus. J. Clin. Microbiol. 52(2): 328-330.

Blanco M., Blanco J.E., Rodríguez E., Abalia I., Alonso M.P. \& Blanco J. 1997. Detection of virulence genes in uropathogenic Escherichia coli by polymerase chain reaction (PCR): comparison with results obtained using phenotypic methods. J. Microbiol. Meth. 31:37-43.

Boehm D.F., Welch R.A. \& Snyder I.S. 1990. Calcium is required binding of Escherichia coli hemolysin (HlyA) to erythrocyte membranes. Infect. Immun. 58(6):951-1958.

Boufleur R. 2009. Campylobacter jejuni em frangos de corte, carne e vísceras de frango no Rio Grande do Sul e efeito do congelamento sobre a contaminação nos cortes. Dissertação de Mestrado em Medicina Veterinária, Universidade Federal de Santa Maria, Santa Maria, RS. 47p.

Brasil 2003. Instrução Normativa n.70, de 6 de outubro de 2003. Programa de redução de patógenos: monitoramento microbiológico, controle de Salmonella sp. em carcaças de frangos e perus. Disponível em <http://www.avisite.com.br/legislação/in 70 reduc patogenos.asp> Acesso em 19 fev. 2014.

Canals I. \& Rossel A. 2002. Campylobacteriosis en aves de corral [on-line]. C.Vet. Cata. Espanha. Disponível em <http://www.colvet.es/infovet. ene02/ciencias_v/articulo1.htm> Acesso em 28 dez. 2013.

Carbonell G.V. \& Vidotto M.C. 1992. Virulence factors in Serratia marcescens: cell bound hemolysin and aerobactin. Braz. J. Med. Biol. Res. 25:1-8.
Chart H., Jenkins C., Smith H.R., Hedges D. \& Rowe B. 1998. Haemolysin production by strain of verocytoxin-producing Escherichia coli. Microbiol. 144:103-107.

Carvalho A.C.F.B. \& Cortez A.L.L. 2007. Campylobacteriose Aviária, p.144150. In: Andreatti Filho L.P. (Ed.), Saúde Aviária e Doenças. Roca, São Paulo.

Carvalho A.F., Silva D.M., Azevedo S.S., Piatti R.M., Genovez M.E. \& Scarcelli E. 2010. Deteç̧ão dos genes da toxina citoletal distensiva em cepas de Campylobacter jejuni isoladas de carcaças de frangos. Arq. Bras. Med. Vet. Zootec. 62(5):1054-1061.

Chamovitz B.N., Hartstein A.I., Alexander S.R., Terry A.B., Short P. \& Katon R. 1983. Campylobacter jejuni - associated hemolytic-uremic syndrome in a mother and daughter. Pediatrics 71(2):253-256.

Dasti J.I., Tareen A.M., Lugert R., Zautner A.E. \& Grob U. 2010. Campylobacter jejuni: a brief overview on pathogenicity: associated factors and disease-mediating mechanisms. Int. J. Med. Microbiol. 300:205-211.

Datta S., Niwa H. \& Itoh K. 2003. Prevalence of 11 pathogenic genes of Campylobacter jejuni by PCR in strains isolated from humans, poultry meat and broiler and bovine faeces. J. Med. Microbiol. 52:345-348.

Fao/Who 2009. Salmonella and Campylobacter in chicken meat. Microbiol. Risk Assess Series Meeting Report, Food and Agriculture Organization of the United Nations Worlds Health Organization. 69p.

Feistel J.C., Rezende C.S.M., Oliveira J.J., Oliveira A.P. \& Moreira N.M. 2013. Mecanismos de patogenicidade de Campylobacter spp. isolado em alimentos. Enciclopédia Biosfera, Centro Científico Conhecer, 9(17):18611882.

Frost J.A. 2001. Current epidemiological issue in human campylobacteriosis. J. Appl. Microbiol. 90:85S-95S.

FSA 2011. Food Disease Strategy 2010/15. Food Standards Agency, United Kingdom (Online). Disponível em <http://www.food.gov.uk/multimedia/pdfs2015.pdf> Acesso em 9 jan. 2014.

Hanel I., Borrmann E., Muller J. \& Atler T. 2007. Relationships between bacterial genotypes and in vitro virulence properties of Campylobacter jejuni and Campylobacter coli isolated from Turkeys. J. Appl. Microbiol. 102:433-441.

Hossain A., Stewart-Tull D.E.S. \& Freer J.H. 1993. Heat-labile and heatstable haemolysins of Campylobacter jejuni. FEMS Immun. Med. Microbiol. 6:331-340.

Kabir S.M.L., Kikuchi K., Asakura M., Shiramaru S., Tsuruaka N., Goto A., Hininoya A. \& Yamasaki S. 2011. Evaluation of Cytolethal Distending Toxin $(c d t)$ gene-based species-specific Multiplex PCR assay for the identification of Campylobacter strains isolated from diarrheal patients in Japan. Jpn. J. Infect. Dis. 64:19-27.

Lara-Tejero M. \& Galán J.E. 2001. $C d t \mathrm{~A}, C d t \mathrm{~B}$, and $C d t \mathrm{C}$ from a tripartite complex that is required for cytolethal distending toxin activity. Infect. Immun. 69(7):4358-4365.

Martinez I., Mateo E., Churruca E., Girbau C. \& Fernandez-Astorga R.A.A. 2006. Detection of $c d t \mathrm{~A}, c d t \mathrm{~B}$ and $c d t \mathrm{C}$ genes in Campylobcter jejuni by multiplex PCR. Int. J. Med. Microbiol. 296(1):45-48.

Medeiros V.M. 2011. Isolamento e identificação fenotípica e molecular das espécies termofílicas de Campylobacter a partir de frango resfriado. Dissertação de Mestrado, Fundação Osvaldo Cruz./Fiocruz, Rio de Janeiro, RJ. 94p.

Misawa N., Hirayama K., Itoh K. \& Takahashi E. 1995. Detection of alfa and beta-hemolytic: like activity from Campylobacter jejuni. J. Clin. Microbiol. 33(3):729-731.

Park S.F. 2002. The physiology of Campylobacter species and its relevance to their role as foodborne pathogens. J. Food Microbiol. 74:177-188.

Perdoncini G. 2012. Prevalência de Campylobacter jejuni e C. coli em carcaças de aves após o pré-resfriamento por imersão. Monografia de Especialização em Produção, Tecnologia e Higiene de Produtos de Origem Animal, Universidade Federal do Rio Grande do Sul, Porto Alegre, RS. 35p.

Pickett C.L., Auffenberg T., Pesci E.C., Sheen V.L. \& Jusuf S.S.D. 1992. Iron acquisition and hemolysin production by Campylobacter jejuni. Infect. Immun. 60:3872-3877. 
Rowe G.E. \& Welch R.A. 1994. Assays of hemolytic toxins. Meth. Enzymol. 235:657-667.

Rozynek E., Dzierzanowska-Frangat K., Jozwiak P., Popowski J., Korsak D. \& Dzierzanowska D. 2005. Prevalence of potential virulence markers in Polish Campylobacter jejuni and Campylobacter coli isolates obtained from hospitalized children and from chicken carcasses. J. Med. Microbiol. 54:615-619.

Scallan E., Hoekstra R.M., Angulo F.J., Tauxe R.V., Widdowson M.A., Roy S.L., Jones J.L. \& Griffin P.M. 2011. Foodborne illness acquired in the United States-major pathogens. Emerg. Infect. Dis. 17:7-15.

Smith J.L. \& Bayles D.0. 2006. The contribution of cytolethal distending toxin to bacterial pathogenesis. Crit. Rev. Microbiol. 32(4):227-248.

Silva J., Leite D., Fernandes M., Mena C., Gibbs P.A. \& Texeira P. 2011. Campylobacter spp. as foodborne pathogen: a review. Front. Microbiol. 2:1-12.

Simi S. 2004. Caracterização físico-química e biológica de uma hemolisina de baixo peso molecular produzida por linhagem clínica de Enterobacter cloacae. Tese de Doutorado, Universidade Estadual de Campinas, Campinas, SP. 72p.

Talukder K.A., Aslam M., Islam Z., Azm I.J., Dutta D.K., Hossain S., Nur-E-Kamal A., Nair G.B., Cravioto A., Sack D.A. \& Endtz H.P. 2008. Prevalence of virulence genes and cytolethal distending toxin, production in Campy- lobacter jejuni isolates from diarrheal patients in Bangladesh. J. Clin. Microbiol. 4(4):1485-1488.

Tay S.T., Devi S., Puthucheary S.D. \& Kautner I.M.1995. Detection of haemolytic acticity of Campylobacters by agarose haemolysis and microplate assay. J. Med. Microbial. 42:175-180.

Thomé J.D.S. 2006. Citotoxinas e hemolisinas produzidas por Campylobacter jejuni isolados de diferentes origens. Dissertação de Mestrado, Universidade Estadual de Campinas, Campinas, SP. 88p.

Van Deun K., Haesbrouck F., Heyndrickx M., Favoreel H., Dewulf J., Ceelen L., Dumez L., Messens W., Leleu S., Immerseel F.V., Ducatelle R. \& Pasmans F. 2007. Virulence properties of Campylobacter jejuni isolates of poultry and human origin. J. Med. Microbiol. 56:1284-1289.

Van Vliet A.H.M. \& Ketley J.M. 2001. Pathogenesis of enteric Campylobacter infection. J. Appl. Microbiol. 90:45S-56S.

Wardak S. \& Szych J. 2006. Prevalence of pathogenic genes of Campylobacter jejuni isolated from humans in Poland between 2003-2005. Med. Dosw. Mikrobiol. 58:217-222.

Wassenaar T.M. \& Newell D.G. 2000. Genotyping of Campylobacter spp. Appl. Environ. Microbiol. 66(1):1-9.

Wieczorek K. \& Osek J. 2008. Identification of virulence genes in Campylobacter jejuni and C. coli isolates by PCR. Bull. Vet. Inst. Pulawy 52:211-216. 